\title{
Study on the influence of water-rock interaction on streamflow conductivity based on hydrograph separation
}

\author{
Weifei Yang ${ }^{1}$, Changlai Xiao, ${ }^{1, *}$, Xiujuan Liang ${ }^{1}$, and Zhihao Zhang ${ }^{1}$ \\ ${ }^{1}$ Key Laboratory of Groundwater Resources and Environment, Ministry of Education, and National- \\ Local Joint Engineering Laboratory of In-situ Conversion, Drilling and Exploitation Technology for \\ Oil Shale, and College of New Energy and Environment, Jilin University, No 2519, Jiefang Road, \\ Changchun 130021, PR China
}

\begin{abstract}
The conductivity of the streamflow is controlled by the content of the dissolved components, which mainly come from the water-rock interaction of the baseflow. This paper showed that the conductivity sequence controlled by water-rock interaction in the runoff process can be screened out by the two-parameter recursive filter method. The analysis of the streamflow and conductivity series of USGS gauge numbered 02298202 from October 2005 to October 2009 showed that the water-rock interaction controls the conductivity characteristics of the stage of streamflow recession. And with the increase of water-rock interaction time $(T)$, the conductivity of the streamflow increases in a power function, which satisfies the equation $C=252.92 T^{0.262}$.
\end{abstract}

\section{Introduction}

Streamflow is usually composed of surface runoff and baseflow, where the baseflow is the discharge of groundwater that has undergone long-term water-rock interactions, while the surface runoff comes directly from precipitation without water-rock interaction [1]. The baseflow typically contains a large number of dissolved components with significantly higher conductivity, while the conductivity of the surface runoff is generally lower and stable [2]. The streamflow in flood season is mainly composed of surface runoff, while in the dry season it is mainly composed of baseflow, so the streamflow conductivity is negatively correlated with the streamflow [3]. Based on the characteristics of streamflow conductivity, many studies have tried to use electrical conductivity as a tracer for hydrograph separation [4-7]. These studies assume that the conductivity of the baseflow is constant and approximately equal to that of the streamflow in the dry season, ignoring the variation of the conductivity with the time of water-rock interaction. A thorough study of the relationship between water-rock interaction and the fluctuation of streamflow conductivity will be helpful to the rational separation and management of stream water resources.

\footnotetext{
*Corresponding author: xcl2822@126.com
} 
There are many methods to divide streamflow into baseflow and surface runoff. The filtering method is favored by many researchers because of its simplicity and easy operation [8]. The two-parameter recursive filtering method is a separation method with higher watershed characteristics derived by substituting $\mathrm{BFI}_{\max }$ into the traditional singleparameter digital recursive filtering (DRF) [9]. The parameters of the two-parameter recursive filtering method all have a reasonable method to determine, and the separation results can be better fit with other methods [10], which has been widely used in previous studies [11].

When the baseflow accounts for a relatively large proportion of the stream flow, the conductivity is mainly controlled by the water-rock interaction [5]. According to the separation results of the two-parameter recursive filtering method, a conductivity series with the daily average baseflow ratio ( $f_{b f}$, the ratio of daily baseflow and total streamflow) greater than 0.9 can be screened, which can be used to identify the characteristics of streamflow conductivity directly controlled by water-rock interaction.

Taking the streamflow and conductivity monitoring data of the USGS gauge numbered 02298202 from October 2005 to October 2009 as an example, this paper expounded the process of exploring the influence of water-rock interaction on streamflow conductivity based on hydrograph separation. This hydrological gauge is located in Shell Creek, Florida, at Latitude $26^{\circ} 59^{\prime} 04^{\prime \prime}$, Longitude $81^{\circ} 56^{\prime} 09^{\prime \prime}$, with a catchment area of $965.7 \mathrm{~km}^{2}$. The streamflow and conductivity process was shown in Fig. 1.

\section{Methods and results}

The equation of the two-parameter recursive filtering method (also called Eckhardt filter) is

$$
b_{k}=\frac{\left(1-B F I_{\max }\right) \alpha b_{k-1}+(1-\alpha) B F I_{\max } y_{k}}{1-\alpha B F I_{\max }}
$$

subject to $b_{k} \leq y_{k}$, where $\alpha$ is the recession constant, BFImax is the baseflow index (the longterm ratio of baseflow to total streamflow), $b_{k}$ is the baseflow and $y_{k}$ is the streamflow in the time step $k$. Eckhardt (2008) gave a regression analysis method for calculating the recession constant based on the assumption that the discharge of aquifer is linearly related to the reserves of the aquifer. By this method, a value of $\alpha=0.978$ was obtained. Eckhardt (2005) suggested that the $\mathrm{BFI}_{\max }$ of perennial streams with porous aquifers should be 0.8 .

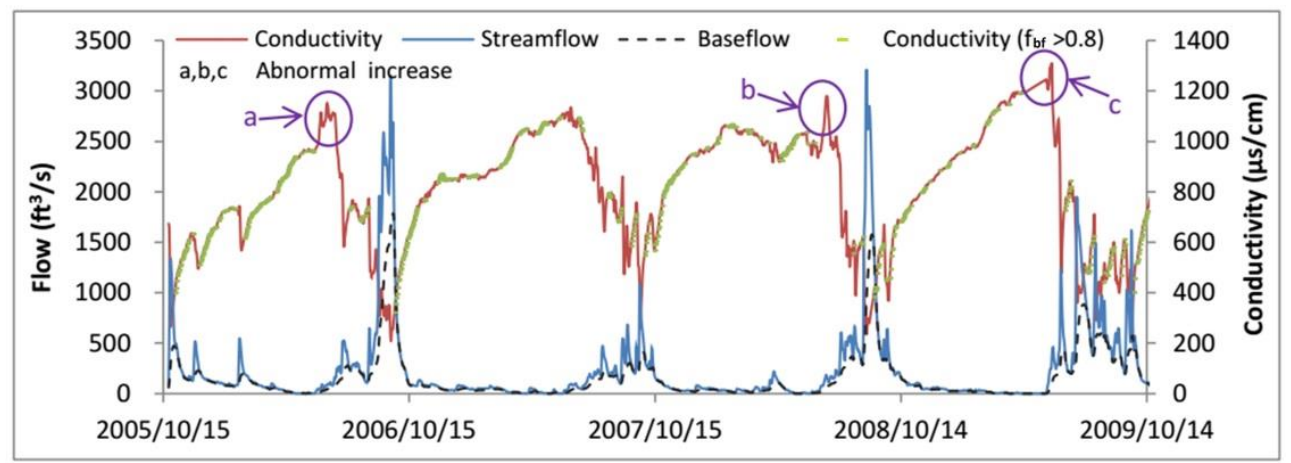

Fig. 1. Multi-year dynamic characteristics of streamflow, baseflow, and conductivity of USGS gauge 02298202 .

Based on the above two-parameter recursive filtering method, the baseflow sequence from October 2005 to October 2009 was separated, and the conductivity sequence whose daily average baseflow ratio $\left(\mathrm{f}_{\mathrm{bf}}\right)$ is greater than 0.9 was selected. The results were shown in 
Fig. 1. It can be seen from the screening results that the conductivity sequence with a baseflow ratio greater than 0.9 (which controlled by water-rock interaction) is mainly distributed in the recession limb of streamflow, and the electrical conductivity increases during recession time. The conductivity in the rising limb of streamflow is significantly reduced, but there are abnormal increases at the beginning of the flood season (Fig. 1).

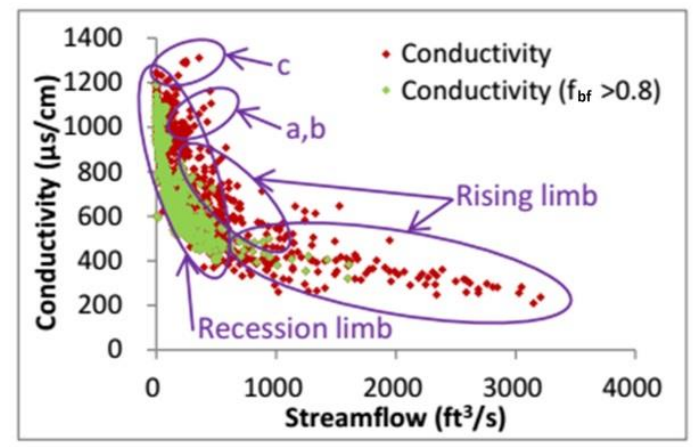

Fig. 2. Scatter plot of conductivity vs. streamflow of USGS gauge 02298202. "a", "b", and "c" are abnormal increase corresponds to that in Fig. 1 respectively.

The relationship between conductivity and streamflow (Fig. 2) shows that there is a negative power function relationship between them. The increasing rate of conductivity controlled by water-rock interaction in the recession limb is greater than the decreasing rate of conductivity in the rising limb. For the same streamflow, the conductivity of the rising limb is greater than the recession limb. The abnormally increasing conductivity in the initial stage of rising limb is positively correlated with the streamflow and obviously deviates from the negative power function relationship.

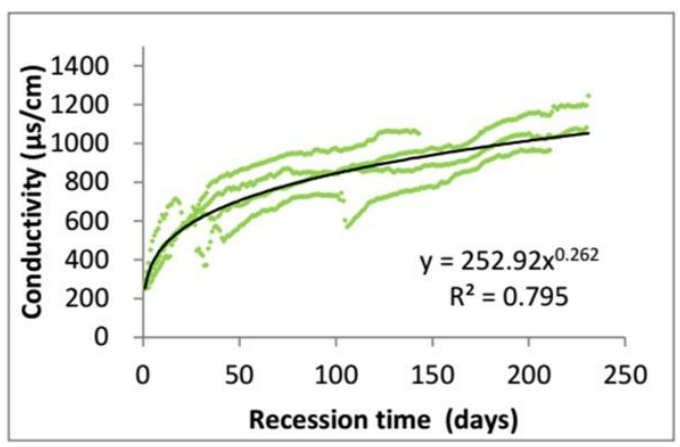

Fig. 3. Scatter plot of streamflow conductivity and recession time (which roughly equates to the time of water-rock interaction) of USGS gauge 02298202.

In order to analyze the influence of water-rock interaction on streamflow conductivity in the recession stage, the relationship between conductivity (with $f_{b f}>0.9$ ) and recession time was plotted (Fig. 3). The recession time was calculated from the time when the maximum flood peak appears for every hydrological year. The recession time is roughly equivalent to the time of water-rock interaction after infiltration of precipitation, so Fig. 3 also reflects the relationship between streamflow conductivity and water-rock interaction time. It can be seen from Fig. 3 that the power function relationship between the outlet conductivity of the studied basin and the water-rock interaction time $(T)$ is

$$
C=252.92 T^{0.262}
$$




\section{Discussions}

With the increase of water-rock interaction time, most of the solutes are close to saturation and the dissolution rate decreases [12], so the increase rate of streamflow conductivity gradually slows down (Fig. 3). The variation of streamflow conductivity with the time of water-rock interaction indicates that there is a great difference in the conductivity of the baseflow in the hydrological process. So the assumption that the conductivity of the baseflow in the hydrological process is constant [4-7] may be unwise.

In the early stage of the streamflow rising limb after long-term low flow, the precipitation drives the high-salinity surface water or shallow groundwater into the river [13], which may be the reason for the abnormal increase of the streamflow conductivity.

\section{Conclusions}

The two-parameter recursive filtering method can help screen out the conductivity sequence controlled by water-rock interaction. Water-rock interaction controls the conductivity characteristics of the streamflow of the recession limb, and the conductivity increases in power function with the water-rock interaction time.

This work is supported by the National Natural Science Foundation of China (41572216), and the Provincial School Co-construction Project Special - Leading Technology Guide (SXGJQY2017-6). We are very grateful to K. Eckhardt for providing the free two-parameter recursive filtering computer program.

\section{References}

1. M. P. Miller, D. D. Susong, C. L. Shope, V. M. Heilweil, B. J. Stolp, Water Resour. Res., 50, 6986-6999 (2014)

2. A. M. L. S. Okello, S. Uhlenbrook, G. P. W. Jewitt, L. Masih, E. S. Riddell, P. V. Zaag, Hydrol. Process., 32, 1334-1350 (2018)

3. M. Stewart, J. Cimino, M. Rorr, Ground Water, 45, 17-27, (2007)

4. D. A. Lott, M. T. Stewart, Ground Water. 51, no. 3, 442-451 (2013)

5. O. Munyaneza, J. Wenninger, S. Uhlenbrook, Hydrol. Earth Syst. Sci., 16, 1991-2004 (2012)

6. I. Cartwright, B. Gilfedder, H. Hofmann, Hydrol. Earth Syst. Sci., 18, 15-30 (2014)

7. D. A. Lott, M. T. Stewart, J. Hydrol. 535, 525-533 (2016)

8. J. F. Costelloe, T. J. Peterson, K. Halbert, A. W. Western, J. J. McDonnell, Hydrol. Earth Syst. Sci., 19, 1599-1613 (2015)

9. K. Eckhardt, Hydrol. Process., 19, 507-515, (2005)

10. K. Eckhardt, J. Hydrol. 352 (1-2), 168-173 (2008)

11. T. B. Kim, J. S. Yang, Hydrol. Process. 31(5), 1161-1173 (2017)

12. Z. Shen, W. Zhu, Z. Zhong, Hydrogeochemical foundation (Geological Publishing House, Beijing, 1993)

13. F. Derek, Karst hydrogeology and geomorphology (China University of Geosciences Press, Wuhan, 2015) 